\title{
Use of a polyphasic approach including MALDI-TOF MS for identification of Aspergillus section Flavi strains isolated from food commodities in Brazil
}

\author{
Fernanda Chaves da Silva • Sara Maria Chalfoun • \\ Luis Roberto Batista • Cledir Santos • Nelson Lima
}

Received: 15 August 2014 / Accepted: 29 January 2015 / Published online: 15 February 2015

(C) Springer-Verlag Berlin Heidelberg and the University of Milan 2015

\begin{abstract}
Brazil is one the largest producers and exporters of food commodities in the world. The evaluation of fungi capable of spoilage and the production mycotoxins in these commodities is an important issue that can be of help in bioeconomic development. The present work aimed to identify fungi of the genus Aspergillus section Flavi isolated from different food commodities in Brazil. Thirty-five fungal isolates belonging to the section Flavi were identified and characterised. Different classic phenotypic and genotypic methodologies were used, as well as a novel approach based on proteomic profiles produced by matrix-assisted laser desorption/ionisation time-of-flight mass spectrometry (MALDI-TOF MS). Type or reference strains for each taxonomic group were included in this study. Three isolates that presented discordant identification patterns were further analysed using the internal transcribed spacer (ITS) region and calmodulin gene sequences. The data obtained from the phenotypic and spectral analyses divide the isolates into three
\end{abstract}

F. C. da Silva $\cdot$ C. Santos $\cdot$ N. Lima

Post-Graduate Programme in Agricultural Microbiology, Federal

University of Lavras, Lavras, MG, Brazil

S. M. Chalfoun

Company of Agricultural Research of Minas Gerais (EPAMIG),

Federal University of Lavras, Lavras, MG, Brazil

L. R. Batista

Department of Food Sciences, Federal University of Lavras, Lavras, MG, Brazil

F. C. da Silva

Instituto Federal do Espirito Santo, Campus Barra de São Francisco, Barra de São Francisco, ES, Brazil

F. C. da Silva $\cdot$ C. Santos $(\bowtie) \cdot$ N. Lima

CEB - Centre of Biological Engineering, Micoteca da Universidade do Minho, Universidade do Minho, 4710-057 Braga, Portugal

e-mail: cledirs@hotmail.com groups, corresponding to taxa closely related to Aspergillus flavus, Aspergillus parasiticus, and Aspergillus tamarii. Final polyphasic fungal identification was achieved by joining data from molecular analyses, classical morphology, and biochemical and proteomic profiles generated by MALDI-TOF MS.

Keywords Aspergillus section Flavi · Food mycology · MALDI-TOF MS · Mycotoxin · Polyphasic identification

\section{Introduction}

The genus Aspergillus is one of the most important microfungi in industry, agriculture, and public health. Since the last taxonomic revision, more than 250 species belonging to this genus have been accepted as being widely distributed in the world (Simões et al. 2013). In addition, some of the most important microorganisms used in food fermentation, enzyme production, and industrial bioprocesses are part of the genus Aspergillus.

The Aspergillus section Flavi comprises 25 species, from which six of them are of economic importance and are very closely related among themselves from a morphological and phylogenetic point of view. Based on their impact on food and/or human health, fungi belonging to the section Flavi are often separated into two groups (Godet and Munaut 2010). The first group includes Aspergillus flavus, A. parasiticus and A. nomius. Some strains of this group of species are reported to be producers of aflatoxins. The second group comprises $A$. oryzae, A. sojae and A. tamarii. These species are described as non-producers of aflatoxins and are normally used in Asian countries for fermenting processes (Kumeda and Asao 2001; Hedayati et al. 2007).

The identification of Aspergillus section Flavi has traditionally been based on macro- and micro-morphological and biochemical traits (Raper and Fennel 1965; Samson et al. 
2000; Rodrigues et al. 2011). The macromorphological traits include conidial and colony colour, colony diameter, colony reverse colour, production of exudates and soluble pigments, and the presence of sclerotia and cleistothecia, while the micromorphology traits include seriation, shape, and size of the vesicle, conidia and stipe morphology, the presence of Hülle cells, and morphology of cleistothecia and ascospores (Klich 2002).

From a biochemical traits point of view, some strains of A. flavus have been considered to produce aflatoxins $\mathrm{B}$ (AFBs) and/or cyclopiazonic acid (CPA). However, A. flavus is not considered to produce aflatoxins $\mathrm{G}$ (AFGs). On the other hand, some $A$. parasiticus strains are able to produce AFB1, AFB2, AFG1 and AFG2. Nevertheless, this fungal species has not been described as a producer of CPA (Bennett and Klich 2003; Yu et al. 2004).

Other species comprising the Aspergillus section Flavi, namely $A$. toxicarius, $A$. nomius, $A$. bombycis, and A. pseudotamarii, have also been described as producers of AFBs and CPA. In contrast, $A$. oryzae has not been described as a producer of AFBs, although it can produce CPA and $\beta$ nitropropionic acid. Furthermore, the species $A$. oryzae, $A$. parasiticus, A. sojae, A. nomius, A. bombycis, A. tamarii, $A$. caelatus, and A. pseudotamarii may also produce kojic acid (Varga et al. 2003).

Over the past few years, molecular methods have been widely applied to the identification of different microbial taxa, including a large number of Aspergillus species (Batista et al. 2008; Rodrigues et al. 2009, 2011; Lima-Neto et al. 2014; Midorikawa et al. 2014; Nicolau et al. 2014). Molecular traits provide the greatest number of variable characters for fungal taxonomy. Molecular technology, when used together with a well-developed bioinformatics toll, allows the comparison of results. It produces data that are generally highly correlated with reproducible phenotypic differences and ensures that molecular characters have a primary role in recognising fungal taxa. Nonetheless, even with the high level of sensitivity and resolution associated with the molecular methods, some problems still arise when this technique is applied for the identification of species within the Aspergillus section Flavi. These difficulties are due to the high level of genetic similarity found in some of species of the Aspergillus section Flavi (Rodrigues et al. 2011).

Matrix-assisted laser desorption/ionisation time-of-flight mass spectrometry (MALDI-TOF MS) is a technique able to analyse organic compounds, including those of high-weight molecular mass. It works through the soft ionisation of the molecules, resulting in minimum fragmentation (Tanaka et al. 1988). MALDI-TOF MS can be applied to analyse the chemical cellular composition of microorganisms, providing rapid and discriminatory proteomic profiles for their identification and subtyping. The remarkable reproducibility of this technique is based on the measurement of constantly expressed and highly abundant proteins. The usually observable molecular mass range is between 2,000 and 20,000 Da, where important ribosomal proteins appear. It is an advantage because the ribosomal proteins can easily be used as biomarkers (Santos et al. 2010). Recently, proteomic profiles by MALDI-TOF MS have been used as an important step in the polyphasic identification of filamentous fungi isolated from different fields (Santos et al. 2010, 2011; Dias et al. 2011; Rodrigues et al. 2011; Passarini et al. 2013; Pereira et al. 2014).

Consistent identification and characterisation of filamentous fungi species have been developed by application of the so-called polyphasic approach, which involves the use of the various techniques discussed above (e.g., macro- and micromorphology, biochemical, molecular biology, and proteomic profiles by MALDI-TOF MS) ensuring the systematisation of scientific knowledge (Simões et al. 2013). Information obtained from each technique is compared with that from the others in a step-by-step methodology, the molecular techniques of which have been recognised as the gold standard for the identification of Aspergillus species (Simões et al. 2013). The aim of this study was to apply a polyphasic approach for the identification of 35 fungal strains belonging to the section Flavi isolated from different food commodities in Brazil. Furthermore, five additional fungal strains obtained from the Portuguese Culture Collection Micoteca da Universidade do Minho (MUM) were used as reference strains. The polyphasic approach consisted of macro- and micro-morphology, biochemical analyses, proteomic profiling by MALDI-TOF MS, and molecular biology using the ITS region of the rRNA gene and partial calmodulin gene.

\section{Material and methods}

Fungal isolates and culture conditions

Thirty-five isolates of Aspergillus section Flavi were isolated from food commodities (coffee, maize, Brazil nuts, peanuts, rice, and cereal snack bars) acquired at a local market in the city of Lavras (MG), Brazil. After purification and identification, the isolates were deposited at the EcoCentro Mycological Collection of the Company of Agricultural Research of Minas Gerais (EPAMIG, http://www.epamig.br/), Lavras (MG), Brazil.

The code "CMEcoCentro 000nn" was attributed for each fungal isolate, where " $n$ " means isolate number. The reference strains A. flavus MUM 92.01 (NRRL6412), A. parasiticus MUM 92.02 (NRRL3386), A. oryzae MUM 98.04 (NRRL3484), A. tamarii MUM 92.03 (NRRL 427) and A. sojae MUM 10.241 (CBS 100928) were obtained from the Micoteca da Universidade do Minho (MUM, www.micoteca. deb.uminho.pt/) Culture Collection, Braga, Portugal. 


\section{Morphological characterisation}

All 35 isolates were submitted to the observation of macro- and micro-morphological traits. For the macro-morphological analysis, all isolates were grown and maintained on malt extract agar (MEA: malt $20 \mathrm{~g} \mathrm{~L}^{-1}$, glucose $20 \mathrm{~g} \mathrm{~L}^{-1}$, peptone $1 \mathrm{~g} \mathrm{~L}^{-1}$, agar $20 \mathrm{~g} \mathrm{~L}^{-1}$ ), Czapek yeast autolysate agar (CYA: sucrose $30 \mathrm{~g} \mathrm{~L}^{-1}$, powdered yeast extract $5 \mathrm{~g} \mathrm{~L}^{-1}, \mathrm{~K}_{2} \mathrm{HPO}_{4}$ $1 \mathrm{~g} \mathrm{~L}^{-1}, \mathrm{NaNO}_{3} 2 \mathrm{~g} \mathrm{~L}^{-1}, \mathrm{KCl} 0.5 \mathrm{~g} \mathrm{~L}^{-1}, \mathrm{MgSO}_{4} 7 \mathrm{H}_{2} \mathrm{O}$ $0.5 \mathrm{~g} \mathrm{~L}^{-1}, \mathrm{FeSO}_{4} 7 \mathrm{H}_{2} \mathrm{O} 0.01 \mathrm{~g} \mathrm{~L}^{-1}, \mathrm{ZnSO}_{4} 7 \mathrm{H}_{2} \mathrm{O} 0.01 \mathrm{~g} \mathrm{~L}^{-1}$, $\mathrm{CuSO}_{4} 5 \mathrm{H}_{2} \mathrm{O} 0.005 \mathrm{~g} \mathrm{~L}^{-1}$, agar $20 \mathrm{~g} \mathrm{~L}^{-1}$ ), Czapek yeast extract agar with $20 \%$ sucrose (CY20S: sucrose $200 \mathrm{~g} \mathrm{~L}^{-1}$, yeast extract $5 \mathrm{~g} \mathrm{~L}^{-1}, \mathrm{~K}_{2} \mathrm{HPO}_{4} 1 \mathrm{~g} \mathrm{~L}^{-1}$, Czapek concentrate $10 \mathrm{~mL}$, trace metals solution $1 \mathrm{~mL}$, agar $15 \mathrm{~g} \mathrm{~L}^{-1}$ ) and Czapek medium (CZ: sucrose $30 \mathrm{~g} \mathrm{~L}^{-1}, \mathrm{~K}_{2} \mathrm{HPO}_{4} 1 \mathrm{~g} \mathrm{~L}^{-1}, \mathrm{NaNO}_{3} 2 \mathrm{~g} \mathrm{~L}^{-1}, \mathrm{KCl}$ $0.5 \mathrm{~g} \mathrm{~L}^{-1}, \mathrm{MgSO}_{4} 7 \mathrm{H}_{2} \mathrm{O} 0.5 \mathrm{~g} \mathrm{~L}^{-1}, \mathrm{FeSO}_{4} 7 \mathrm{H}_{2} \mathrm{O} 0.01 \mathrm{~g} \mathrm{~L}^{-1}$, $\mathrm{ZnSO}_{4} 7 \mathrm{H}_{2} \mathrm{O} 0.01 \mathrm{~g} \mathrm{~L}^{-1}, \mathrm{CuSO}_{4} 5 \mathrm{H}_{2} \mathrm{O} 0.005 \mathrm{~g} \mathrm{~L}^{-1}$, agar $20 \mathrm{~g} \mathrm{~L}^{-1}$ ).

Spores of each isolate suspended in $1 \mathrm{~mL}$ of $0.2-\%$ agar were used for three-point inoculations on 9-cm diameter Petri dishes containing $20 \mathrm{~mL}$ of each medium described above. Cultures were incubated for 7 days in the dark at $25^{\circ} \mathrm{C}$ for culture media MEA, CYA and CY20S, at $37{ }^{\circ} \mathrm{C}$ for CYA medium, and at $42{ }^{\circ} \mathrm{C}$ for $\mathrm{CZ}$ medium. For the micromorphological analysis, all isolates were grown on MEA and cultures were incubated for 7 days in the dark at $25^{\circ} \mathrm{C}$, as described above.

In order to confirm group identification by colony reverse colour, all isolates were cultured on Aspergillus flavus and A. parasiticus agar (AFPA, Oxoid, Basingstoke, United Kingdom) for 3 to 5 days at $25^{\circ} \mathrm{C}$ in the dark. All cultures were then analysed for colony colour, presence of sclerotia, head seriation and conidia ornamentation. Fungal identification followed the taxonomic keys and guides available for the Aspergillus genus (Klich 2002; Samson et al. 2004; Rodrigues et al. 2009, 2011).

\section{Biochemical characterisation}

In order to evaluate the ability of a fungus to produce aflatoxin, all 35 isolates were grown on aflatoxin-inducing yeast extract sucrose medium (YES: yeast extract $20 \mathrm{~g} \mathrm{~L}^{-1}$, sucrose $150 \mathrm{~g} \mathrm{~L}^{-1}$, agar $\left.15 \mathrm{~g} \mathrm{~L}^{-1}\right)$. Spores of each isolate suspended in $0.5 \mathrm{~mL}$ of $0.2 \%$ agar were used for inoculation on a single point on 6-cm diameter Petri dishes and incubated at $25^{\circ} \mathrm{C}$ in the dark for 7 days.

For aflatoxin extraction, the methodology described by Rodrigues et al. (2011) was applied. Briefly, three agar plugs were removed from the fungal colony and placed in a 4-mL vial, where $2 \mathrm{~mL}$ of methanol was added. After $60 \mathrm{~min}$, the extract was filtered by $0.45-\mu \mathrm{m}$ filters and analysed by high performance liquid chromatography (HPLC) equipped with a Jasco FP-920 fluorescence detector (365 nm excitation wavelength, $435 \mathrm{~nm}$ emission wavelength), using a photochemical post-column derivatisation reactor (PHRED unit, Aura Industries, New York, NY, USA).

Chromatographic separations were performed on a reversephase C18 column (Waters Spherisorb ODS2, $4.6 \mathrm{~mm} \times$ $250 \mathrm{~mm}, 5 \mu \mathrm{m}$ ) fitted with a pre-column with the same stationary phase. The mobile phase used was pumped at $1.0 \mathrm{~mL} \mathrm{~min}{ }^{-1}$ and consisted of an isocratic programme as follows: water- to-acetonitrile-to-methanol $(3: 1: 1, \mathrm{v} / \mathrm{v} / \mathrm{v})$. The injection volume was $50 \mu \mathrm{L}$.

Aflatoxin standards were supplied by R-Biopharm Rhône Ltd. A mix of aflatoxins containing $1 \mu \mathrm{g} \mathrm{mL}^{-1}$ of AFB1, AFB2, AFG1, and AFG2 was used. Samples were interpreted as positive for each one of the toxins when they yielded a peak at a retention time similar to each standard, with a height fivefold higher than the baseline noise.

In order to evaluate the fungal capacity for producing CPA, all isolates were grown on a single point on 6 - $\mathrm{cm}$ diameter plates containing CYA and incubated at $25^{\circ} \mathrm{C}$ in the dark for 14 days. For the CPA extraction, the methodology described by Rodrigues et al. (2011) was applied.

Samples were analysed using an HPLC equipped with a Varian 2050 UV detector $(285 \mathrm{~nm})$. Chromatographic separations were performed on a Eurospher $100 \mathrm{NH} 2$ column (Knauer, $4.6 \mathrm{~mm} \times 250 \mathrm{~mm}, 5 \mu \mathrm{m}$ ), fitted with a pre-column with the same stationary phase. The mobile phase used was pumped at $1.0 \mathrm{~mL} \mathrm{~min}^{-1}$, and consisted of an isocratic programme as follows: acetonitrile: $50 \mathrm{mM}$ ammonium acetate $(3: 1, \mathrm{v} / \mathrm{v})$ with a $\mathrm{pH}$ of 5.0 . The injection volume was $50 \mu \mathrm{L}$. CPA standard was supplied by Sigma-Aldrich (St. Louis, MO, USA). Samples were interpreted as positive when they yielded a peak at a retention time similar to the CPA standard, with a height fivefold that of the baseline noise.

\section{Phenotypic data analysis}

A dendrogram of phenotypic relatedness was constructed. The characters analysed were both (a) the macro- and micromorphological traits, namely, the head seriation, colony colour on CYA, conidia ornamentation, reverse colony colour on AFPA; and (b) the biochemical traits, namely the production of AFB1 and AFB2, AFG1 and AFG2, and CPA. Statistical analysis was performed based on a hierarchical clustering with the average linkage method (between groups), and was achieved using the statistical package SPSS version 16.0 (IBM/SPSS Inc. Chicago, IL, USA).

\section{Proteomic profile by MALDI-TOF MS}

Seven-day-old spores of each fungal isolate suspended in $0.5 \mathrm{~mL}$ of $0.2 \%$ agar were used for inoculation on a single point on 6-cm diameter Petri dishes with MEA. All isolates were incubated for 3 days at $25{ }^{\circ} \mathrm{C}$. Approximately $1 \mu \mathrm{g}$ of 
mycelium or a mycelium/spore mixture from the growing edge colony was transferred directly from the culture plate to the 48-well MALDI flex target plate (FlexiMass ${ }^{\mathrm{TM}}$, Shimadzu Biotech, Buckinghamshire, UK). Immediately, $0.5 \mu \mathrm{L}$ matrix solution ( $75 \mathrm{mg} \mathrm{mL}^{-1}$ 2,5-dihydroxybenzoic acid [DHB] in ethanol/water/acetonitrile [1:1:1] with $0.03 \%$ trifluoroacetic acid [TFA]) was added and mixed gently. Escherichia coli strain DH5 $\alpha$ was obtained from the MUM Culture Collection, and its cells were used for in situ extraction of proteins, which were used as the standard for the MALDI-TOF MS external calibration. Cells of E. coli DH5 $\alpha$ were grown on Luria-Bertani medium agar (LB; $10 \mathrm{~g} \mathrm{~L}^{-1}$ bacto-tryptone, $5 \mathrm{~g} \mathrm{~L}^{-1}$ bactoyeast extract, $10 \mathrm{~g} \mathrm{~L}^{-1}$ $\mathrm{NaCl}$ ) at $30^{\circ} \mathrm{C}$ for $20 \mathrm{~h}$. About $1 \mu \mathrm{g}$ of cellular material from a single $E$. coli colony was transferred from the Petri dish to the MALDI flex plate and the matrix solution was applied as described above for the fungal analysis. All sample plates were air dried at room temperature. Each sample was spotted in duplicate to test reproducibility. During the analyses, all solutions were prepared daily and stored at $+5^{\circ} \mathrm{C}$.

Analyses were performed on an Axima LNR MALDI-TOF MS system (Kratos Analytical, Shimadzu, UK) equipped with a nitrogen laser $(337 \mathrm{~nm})$, where the laser intensity was set just above the threshold for ion production. Twelve defined ribosomal proteins of intact $E$. coli $\mathrm{DH} 5 \alpha$ cells $(4,365.4,5,096.8$, 5,381.4, 6,241.4, 6,255.4, 6,316.2, 6,411.6, 6,856.1, 7,158.8, $7,274.5,7,872.1,9,742$ and $12,227.3 \mathrm{Da})$ were used as external calibrants. The mass spectra based on the mass range from 2 to $20 \mathrm{kDa}$ were recorded using the linear mode with a delay of $104 \mathrm{~ns}$ and an acceleration voltage of $+20 \mathrm{kV}$. The final spectra were generated by summing 20 laser shots accumulated per profile and 50 profiles produced per sample, which led to 1,000 laser shots per summed spectrum.

The resulting peak lists were exported to the SARAMISTM software package (Spectral Archiving and Microbial Identification System; AnagnosTec, Zossen, Germany), where the final microbial identification was achieved. In SARAMISTM, peak lists of individual samples were compared to a database, generating a ranked list of matching spectra. This software uses a point system based on the peak list with mass signals weighted according to their specificity. The similarity between individual spectra is expressed as the relative or absolute number of matching mass signals after subjecting the data to a single link agglomerative clustering algorithm. Microbial identifications by the SARAMIS ${ }^{\text {TM }}$ package are based on the presence or absence of each peak in the spectra. A dendrogram of proteomic profile proximity among isolates was created using the SARAMISTM package.

Molecular identification and phylogenetic analysis

The isolates CMEcoCentro 00043, CMEcoCentro 00055, and CMEcoCentro 00095 were subjected to molecular analysis of the ITS region of the rRNA gene and partial calmodulin gene. In both cases, DNA extraction followed the protocol described by Rodrigues et al. (2009). The ITS region (spanning part of the $18 \mathrm{~S}$ rRNA gene, the internal transcribed spacer 1, the $5.8 \mathrm{~S}$ rRNA gene, the internal transcribed spacer 2 and part of the 28S rRNA gene; c.a. $600 \mathrm{bp}$ ) was amplified using the primer pair ITS1 (5'-TCCGTAGGTGAACCTGCGG-3') and ITS4 (5'-TCCTCCGCTTATTGATATGC-3'), as described by White et al. (1990).

Amplification of a portion of the calmodulin gene (comprising part of exon 2 , exons $3-5$, part of exon 6 , and introns $2-5$; c.a. $730 \mathrm{bp}$ ) was set up with the primers CL1 (5'GARTWCAAGGAGGCCTTCTC- $3^{\prime}$ ) and CL2A (5'-TTTT GCATCATGAGTTGGAC-3'), as described by O'Donnell et al. (2000). Polymerase chain reaction (PCR) amplifications were performed on $25 \mu \mathrm{L}$ of a reaction mixture containing $\mathrm{MgCl}_{2}$-free reaction buffer, $1.5-\mathrm{mM} \mathrm{MgCl} 2,1.25 \mathrm{U}$ of Taq polymerase, $200 \mu \mathrm{M}$ of each dNTP, $0.2 \mu \mathrm{M}$ of each primer, and $1 \mathrm{ng} \mathrm{LL}^{-1}$ of template DNA. PCR was carried out as follows: (1) one step at $95^{\circ} \mathrm{C}$ for $5 \mathrm{~min}$; (2) 30 cycles of the following three steps: $30 \mathrm{~s}$ at $95{ }^{\circ} \mathrm{C}, 1 \mathrm{~min}$ at $62{ }^{\circ} \mathrm{C}, 2 \mathrm{~min}$ $72{ }^{\circ} \mathrm{C}$; and (3) one final 5 -min step at $72{ }^{\circ} \mathrm{C}$.

For the calmodulin gene, the initial denaturation was performed at $95{ }^{\circ} \mathrm{C}$ for $2 \mathrm{~min}$. Amplified products were purified using the commercial kit PCR Product Purification JetQuick (Genomed, Lisbon, Portugal) according to the manufacturer instructions. The amplified products were then quantified and subjected to sequencing using the BigDye Terminator Cycle Sequencing Standard Kit for an automated ABI 3730xl DNA Analyser (Applied Biosystems, Foster City, CA, USA). Here, the sets of primers used for sequencing were the same as described above.

Sequences were compared with ITS-rRNA sequence data from strains available at the public databases Genbank (http:// www.ncbi.nem.nih.gov) and CBS Fungal Biodiversity Centre (http://www.cbs.knaw.nl/fungi/BioloMICSSequences.aspx) using the BLAST N sequence match routines. Sequences were aligned using the CLUSTALX program, and phylogenetic and molecular evolutionary analyses were conducted using MEGA version 4.0 (Tamura et al. 2007). To estimate the evolutionary distance, the Kimura two-parameter mode (Kimura 1980) was used. Phylogenetic reconstruction was done using the neighbor-joining (NJ) algorithm, with bootstrap values calculated from 1,000 replicate runs, using the software routines included in the MEGA software.

\section{Results}

Phenotypic characterisation

The results obtained by phenotypic characterisation of all 35 isolates evaluated in this study are summarised in Table 1. 


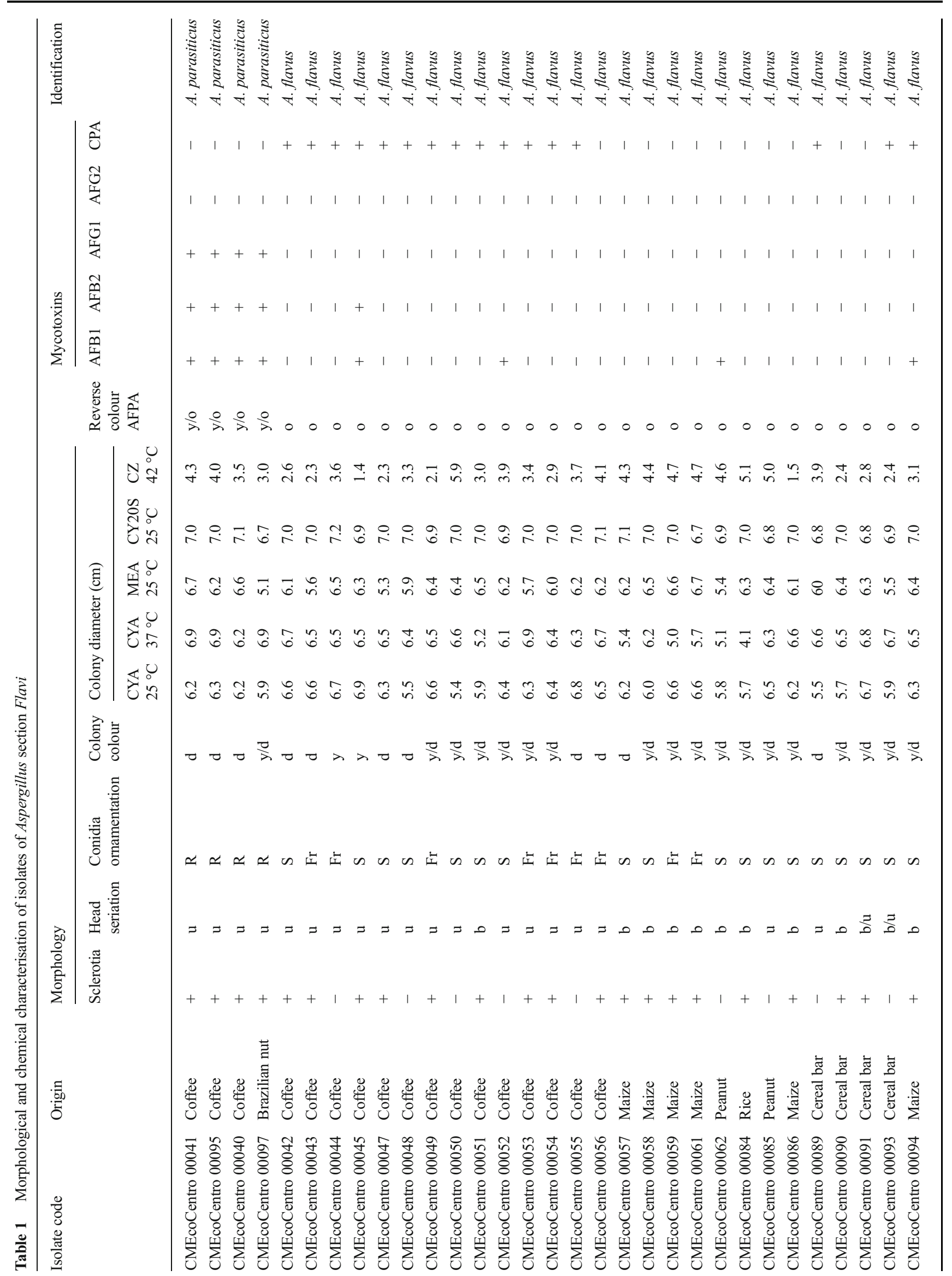




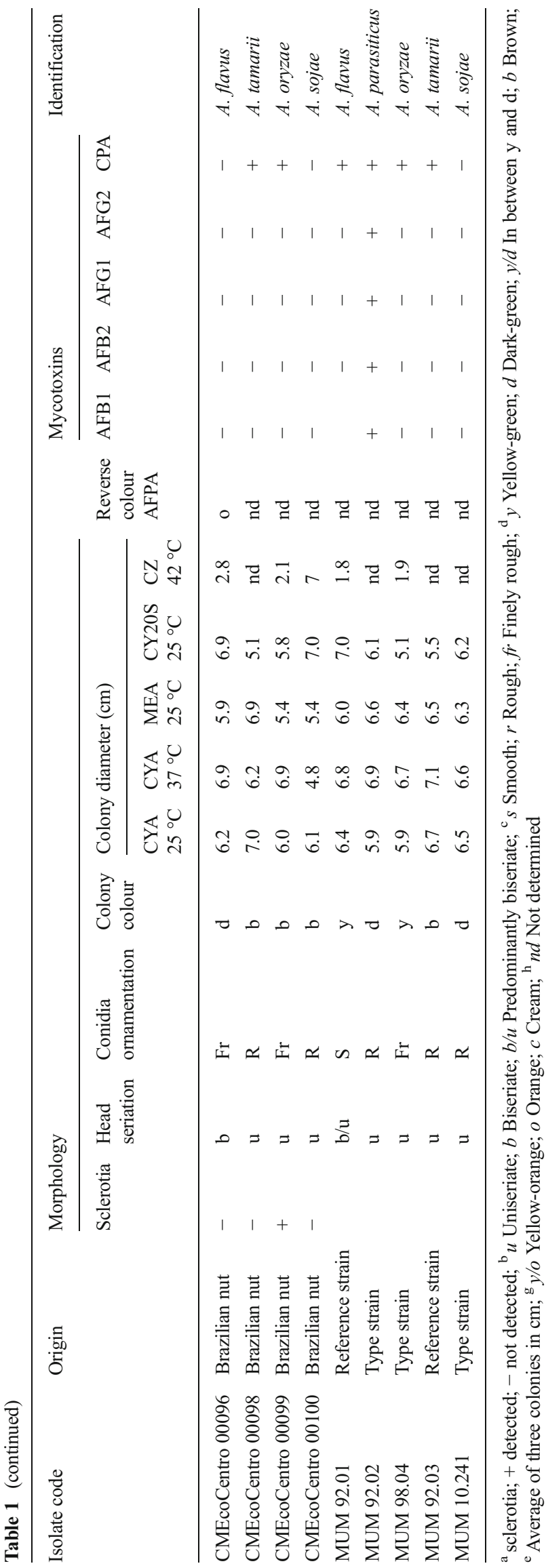

Based on the bright orange or yellow-orange colour of the reverse of the colony on AFPA, all isolates evaluated were classified as belonging to the Aspergillus section Flavi. According to the data obtained from the macro- and micromorphological traits - primarily colony colour on CYA and conidia ornamentation-five different fungal species were found among the whole population under study. The first group of species was A. parasiticus represented by four isolates (c.a. $11 \%$ ) that presented dark-green colonies and rough conidia. The second group of species was A. flavus represented by 28 isolates $(80 \%)$ presenting dark-green to yellow-green colonies, smooth, and from smooth to finely rough conidia. One isolate (c.a. $3 \%$ ) of A. oryzae, A. sojae and A. tamarii, was further morphologically identified. The isolate of the species $A$. tamari presented a brown colony and rough conidia, whereas the isolate belonging to the species $A$. oryzae showed a brown colony and smooth to finely rough conidia. The isolate of the species A. sojae presented a light brown colony and rough conidia (Table 1).

Eighteen isolates (c.a. $51 \%$ ) belonging to A. flavus and 4 isolates (c.a. $11 \%$ ) belonging to A. parasiticus were producers of sclerotia. In addition, 4 isolates (c.a. $11 \%$ ) and 1 isolate (c.a. $3 \%$ ) of A. flavus were producers of AFB1 and AFB2, respectively, while 16 isolates (c.a. $46 \%$ ) of this species were producers of CPA. The production of AFG1 and AFG2 was not detected for the isolates of $A$. flavus. All the 4 isolates belonging to $A$. parasiticus (c.a. $11 \%$ ) were producers of the mycotoxins AFB1, AFB2 and AFG1. On the other hand, the production of $\mathrm{AFG} 2$ and $\mathrm{CPA}$ were not detected by these fungal isolates. As expected, the isolates of the species $A$. oryzae, A. sojae and $A$ tamarii were not detected producing AFB1, AFB2, AFG1 and AFG2. On the other hand, the isolates of $A$. oryzae and $A$. tamarii were producers of CPA (Table 1).

By associating morphotypes to chemotypes of both field isolates and reference strains, all isolates were statistically grouped into four phenotypes (Fig. 1). The phenotype A. parasiticus showed the distinct characteristics described above and clustered forming a single clade in the phenotypic dendrogram. However, the group A. flavus was subdivided into two phenotypes [Fig. 1, A. flavus phenotype (I) and (II)]. From the 14 A. flavus isolates that were grouped as phenotype (I), the following characteristics were observed: 11 isolates (c.a. $79 \%$ ) were biseriate; 10 isolates (c.a. $71 \%$ ) showed smooth conidia; 11 isolates (c.a. $79 \%$ ) presented from yellow-green to dark-green colonies; 4 isolates (c.a. $29 \%$ ) of the whole fungal population of this phenotype were producers of mycotoxins. Furthermore, 9 isolates (c.a. $64 \%$ ) were isolated from maize and its derivatives. On the other hand, from the 14 isolates of $A$. flavus grouped as phenotype (II), the following characteristics were observed: 13 isolates 
Fig. 1 Dendrogram of relatedness among isolates of Aspergillus section Flavi based on the analysis of seriation, colony colour on CYA, conidia ornamentation, reverse on AFPA, AFB production, AFG production, CPA production, and origin of the isolate

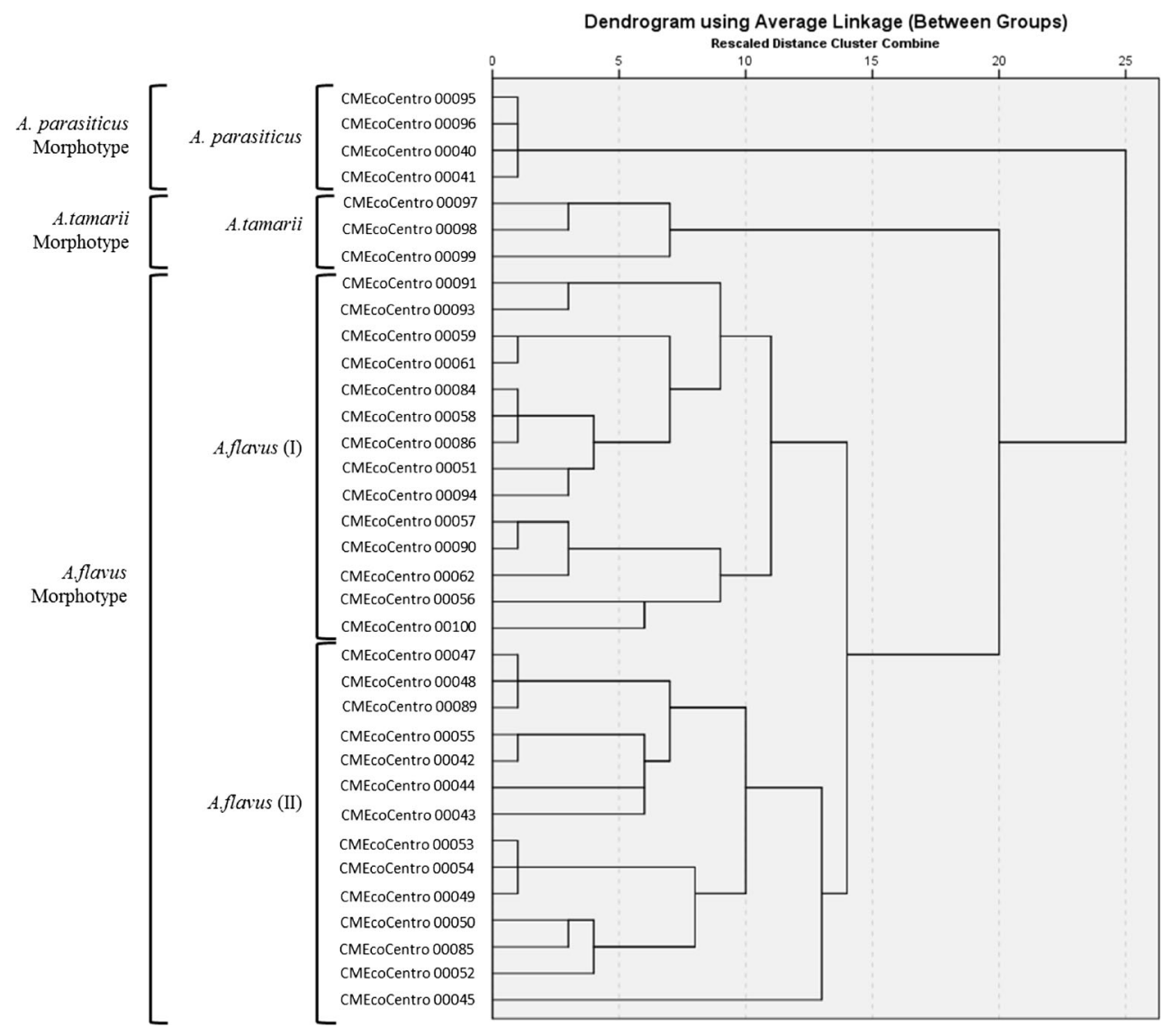

(93\%) were producers of mycotoxins; all of them (14 isolates, $100 \%$ ) were uniseriate; 8 isolates (c.a. $57 \%$ ) presented smooth conidia and 6 isolates (c.a. $43 \%$ ) presented finely rough conidia; 6 isolates (c.a. $43 \%$ ) presented dark green colony colour; 12 of them (c.a. $86 \%$ ) were isolated from coffee. The phenotype $A$. tamarii comprises the isolates of the non-mycotoxigenic strains, namely, A. oryzae, A. sojae, and $A$. tamarii.

\section{Proteomic profiles by MALDI-TOF MS}

Figure 2 shows the dendrogram of relatedness based on proteomic profiles by MALDI-TOF MS, including all 35 isolates evaluated in this study and the reference strains $A$. flavus MUM 92.01 and $A$. tamarii MUM 09.03 (NRRL 427), and the type strains $A$. oryzae MUM 98.04 (NRRL3484) and A. sojae MUM 10.241 (CBS 100928). Also, the reference strain Trichophyton rubrum MUM 08.05 was used as an outgroup and was included in the dendrogram. In this analysis, the following distribution for the field isolates was obtained: 14 isolates of $A$. flavus (I) (c.a. $52 \%$ of all $A$. flavus isolates); 10 isolates of $A$. flavus (II) (c.a. $37 \%$ of all $A$. flavus isolates); 4 isolates of $A$. flavus (III) (c.a. $15 \%$ of all $A$. flavus isolates); and 4 isolates of $A$. parasiticus (100\% of A. parasiticus isolates).
Molecular identification

Data derived from phylogenetic analyses of ITS regions for the three strains A. flavus CMEcoCentro 00043, CMEcoCentro 00055, and CMEcoCentro 00095 was not resolved well enough in this study. Based on the analysis of the ITS region, a cluster containing these three A. flavus strains separated from the sequences of other strains such as $A$. flavus MUM 10.209 (HQ340107), A. flavus NRRL 32354 (HQ288050), and $A$. oryzae NRRL 35191 (EF591304) was obtained (data not shown). For the molecular analysis of the calmodulin gene, it can be observed that both samples CMEcoCentro 00043 and CMEcoCentro 00055 clustered with the sequence of $A$. flavus MUM 10.209 (HQ340087) with $99 \%$ BLAST similarity (Table 2). Moreover, the isolate CMEcoCentro 000100 clustered with sequences of $A$. oryzae NRR 447 (EF661506), A. oryzae CBS 466.91 (FN594585), and $A$. flavus NRRL 4822 (EF661513), also with $99 \%$ BLAST similarity (Table 2).

\section{Discussion}

In the present study, 35 isolates of Aspergillus section Flavi were evaluated using a polyphasic approach. Morphological 
Fig. 2 Dendrogram of proteomic relatedness among isolates of Aspergillus section Flavi based on MALDI-TOF MS. Distances are measured as a percentage of spectral similarity; * reference strains; ${ }^{\mathrm{T}}$ type strains

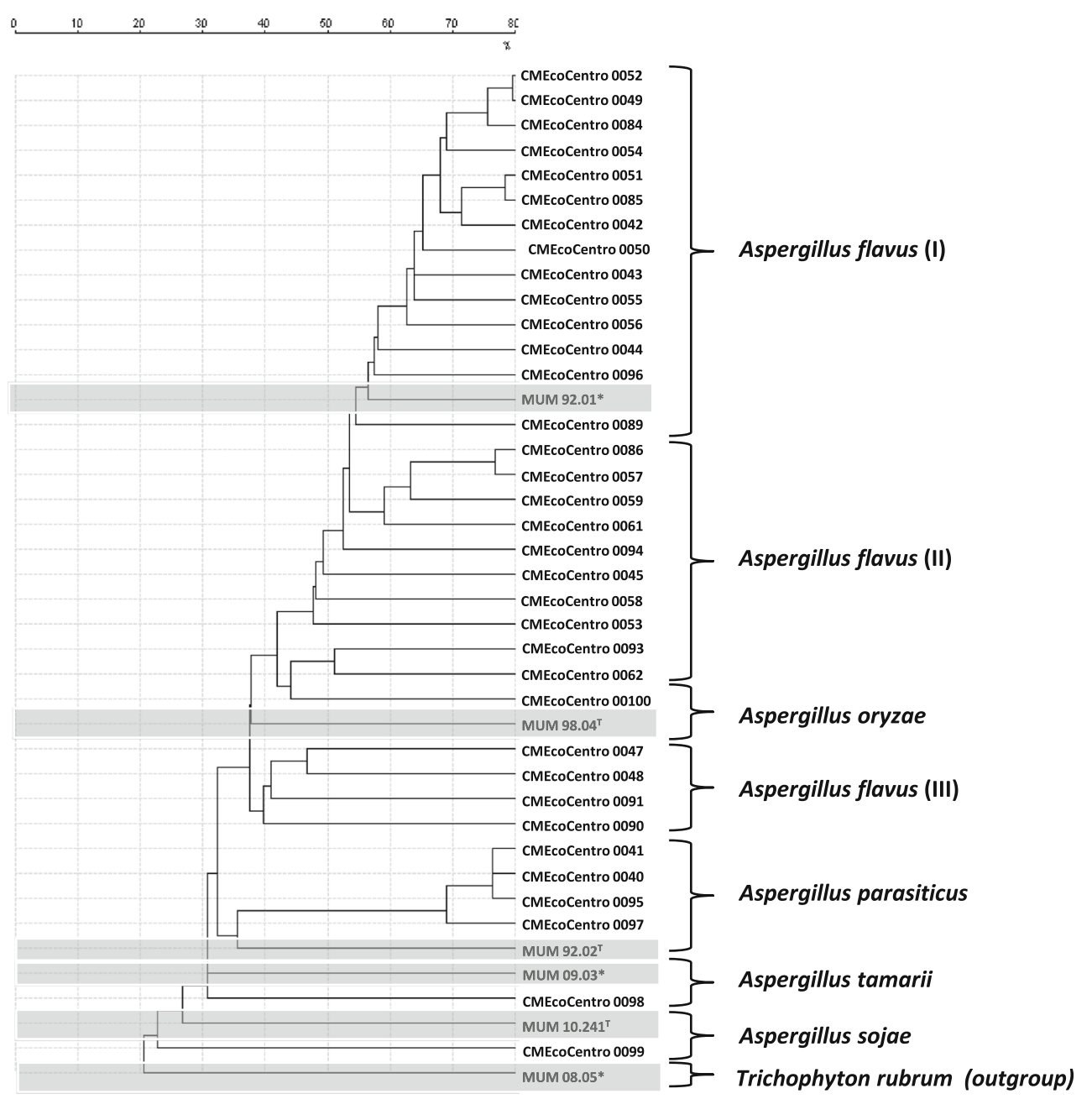

differentiation of species belonging to this group is difficult due to both interspecific similarities and intraspecific variability. In this analysis, colony colour on CYA, conidia ornamentation, and production of the mycotoxins AFB1, AFB2, AFG1, and AFG2 retained their high association with the species. However, in some cases, this specific association is found at lower levels than those expected for phenotypic identification.

Aspergillus flavus and A. parasiticus are morphologically distinguished by colony colour and texture of the wall of conidia (Klich and Pitt 1988). According to Rodrigues et al. (2009, 2011), this differentiation can be improved by the use of a mycotoxigenic profile of each species. Aspergillus parasiticus produces AFBs and AFGs but not CPA, and A. flavus produces AFBs and CPA, but not AFGs. Aflatoxin production by $A$. tamarii has been reported in the literature (Goto et al. 1996; Ito et al. 2001). On the other hand, A. oryzae and $A$. sojae are considered non-mycotoxigenic variants of A. flavus and A. parasiticus, respectively (Kurtzman et al. 1987).

In the present study, 18 (c.a. $51 \%$ ) isolates of $A$. flavus and 4 isolates (c.a. $11 \%$ ) of $A$. parasiticus were producers of sclerotia. However, the production of sclerotia was not directly related to the production of aflatoxins for these isolates of A. flavus and A. parasiticus. Kozakiewicz (1989) reported that the production of sclerotia was a rare characteristic of $A$. flavus strains. According to Klich (2007), the presence of sclerotia per se does not seem to be related to the production of aflatoxins. According to this author, however, the presence of small sclerotia appears to correlate with high aflatoxin production. Different authors have tried to establish a correlation between the ability to produce sclerotia and aflatoxigenicity (Chang et al. 2001; Pildain et al. 2004; Razzaghi-Abyaneh et al. 2006; Giorni et al. 2007). However, data published in the literature are contradictory. Some studies refer to a positive correlation between high production of aflatoxin and the presence of small sclerotia (Novas and Cabral 2002; Pildain et al. 2004), whereas other studies report no correlation between production/size of sclerotia and aflatoxigenicity (RazzaghiAbyaneh et al. 2006; Giorni et al. 2007).

The genomic similarity between $A$. flavus and A. oryzae was shown by the molecular analysis of the calmodulin gene (Table 2). Previous phylogenetic studies indicated that $A$. oryzae may have originated from either an ancestral non- 
Table 2 Aspergillus section Flavi identification and data from sampling, isolation and accession numbers

\begin{tabular}{|c|c|c|c|}
\hline Strain & Source & $\begin{array}{l}\text { Molecular identification } \\
\text { BLAST similarity }\end{array}$ & $\begin{array}{l}\text { Molecular and morphological } \\
\text { identification }\end{array}$ \\
\hline \multirow[t]{3}{*}{ CMEcoCentro 00045} & \multirow[t]{3}{*}{ Brazil coffee } & $\begin{array}{l}99 \text { \% Aspergillus flavus MUM } 10.209 \text { (HQ340087) } \\
98 \% \text { Aspergillus oryzae NRRL } 447 \text { (EF661506) }\end{array}$ & \multirow[t]{3}{*}{ A. flavus } \\
\hline & & 98 \% Aspergillus effusus NRRL 506 (JN185447) & \\
\hline & & $96 \%$ Aspergillus parasiticus NRRL 4123 (EF661518) & \\
\hline \multirow[t]{4}{*}{ CMEcoCentro 00043} & \multirow[t]{4}{*}{ Brazil coffee } & $\begin{array}{l}99 \% \text { Aspergillus flavus NRRL } 3357 \text { (AY974340) } \\
99 \% \text { Aspergillus flavus MUM } 10.209 \text { (HQ340087) }\end{array}$ & \multirow[t]{4}{*}{ A. flavus } \\
\hline & & 99 \% Aspergillus oryzae NRRL 447 (EF661506) & \\
\hline & & 99 \% Aspergillus effusus NRRL 506 (JN185447) & \\
\hline & & 97 \% Aspergillus parasiticus MUM 10.210 (HQ340088) & \\
\hline \multirow[t]{4}{*}{ CMEcoCentro 00100} & \multirow[t]{4}{*}{ Brazil nut } & $\begin{array}{l}99 \% \text { Aspergillus oryzae NRRL } 447 \text { (EF661506) } \\
99 \% \text { Aspergillus flavus NRRL } 4822 \text { (EF661513) }\end{array}$ & \multirow[t]{4}{*}{ A. flavus } \\
\hline & & 99 \% Aspergillus effusus NRRL 506 (JN185447) & \\
\hline & & $99 \%$ Aspergillus oryzae CBS 466.91 (FN594585) & \\
\hline & & 97 \% Aspergillus parasiticus MUM 10.210 (HQ340088) & \\
\hline
\end{tabular}

aflatoxigenic variant of $A$. flavus (Chang et al. 2006), or may have lost the ability to produce aflatoxins during the domestication process (Samson et al. 2000). Rokas et al. (2007) reported that A. flavus, A. parasiticus, A. oryzae and A. sojae have been shown to possess high degrees of DNA relatedness. Aspergillus flavus and A. oryzae have been considered virtually impossible to discriminate. This is also the case with A. parasiticus and A. sojae (Hedayati et al. 2007).

The close relatedness among these four species of the section Flavi (A. flavus, A. parasiticus, A. oryzae and A. sojae), paralleled with their striking difference in terms of aflatoxigenicity and industrial applications, is the foremost example of the challenge posed to the accurate classification of section Flavi species (Rodrigues et al. 2011).

The proteomic profiles obtained via MALDI-TOF MS generated clades (Fig. 2) similar to those found on the phenotypic dendrogram (Fig. 1). The proteomic analysis was not able to separate the aflatoxigenic and non-aflatoxigenic isolates of A. flavus. Also, based on the proteomic clustering, A. oryzae (CMEcoCentro 000100) was not clearly differentiated from A. flavus. For that reason, from a proteomic perspective, it cannot be undoubtedly stated that A. flavus and A. oryzae constitute different species. Studies by Rodrigues et al. (2011) identifying Aspergillus section Flavi isolated from almonds using the polyphasic approach found the same technical limitation. Li et al. (2000) analysed intact spores of isolates of $A$. flavus, $A$. parasiticus, $A$. oryzae and $A$. sojae by MALDITOF MS and found that aflatoxigenic strains and nonaflatoxigenic strains have different mass peak profiles. However, only a few non-informative MALDI-TOF MS spectra were presented in this study. No statistical analysis was performed and no dendrogram of relatedness was presented to prove that statement. Furthermore, the aflatoxigenic $A$. flavus strains used in that study produced both AFBs and AFGs, which, is an atypical feature of $A$. flavus.

Overall, the classical phenotypic approaches, including macro- and micromorphology and mycotoxigenic profiles, were time-consuming, not completely straight forward, and dubious results made accurate identification difficult to attain. However, this classical methodology is still of great value for species identification when integrated within a polyphasic approach (Simões et al. 2013). In addition, the use of the proteomic profile by MALDI-TOF MS increased the reliability of the results obtained in this study. This technique shows potential for discriminating different taxa, which is otherwise feasible only with molecular biology techniques. Moreover, its low cost and the answer time renders the proteomic approach by MALDI-TOF MS a useful toll in the microbial classification/identification of species of Aspergillus section Flavi.

In this study, a molecular technique providing a large number of variables for the taxonomy of fungi was used as the gold standard in the polyphasic methodology described herein. According to the results obtained, the ITS gene was not powerful enough for discrimination of the isolates evaluated molecularly in this study. On the other hand, the calmodulin gene was more informative for the identification analysis of the isolates under investigation. Molecular analyses of both ITS and calmodulin genes were unable to distinguish the isolate $A$. flavus (CMEcoCentro 00100). However, this isolate was identified as $A$. flavus using classical techniques and by the proteomic profiles. This result demonstrates that in a polyphasic approach, none of the methods should be underestimated, and the identification of a species of the Aspergillus section Flavi should consider all characteristics analysed. 
Acknowledgments Acknowledgments are due to FAPEMIG Fundacao de Amparo a Pesquisa do Estado de Minas Gerais (Brazil) for financial support. F. C. da Silva extends thanks to CAPES Coordenacao de Aperfeicoamento de Pessoal de Nivel Superior (Brazil) for the $\mathrm{PhD}$ grant. C. Santos and N. Lima thank CAPES for the financial support as international visiting professors in the Post-Graduate Programme in Agricultural Microbiology, Federal University of Lavras, Lavras (MG), Brazil.

\section{References}

Batista PP, Santos JF, Oliveira NT, Pires APD, Motta CMS, Luna-Alves LEA (2008) Genetic characterization of Brazilian strains of Aspergillus flavus using DNA markers. Gen Mol Res 7:706-717

Bennett JW, Klich M (2003) Mycotoxins. Clin Microbiol Rev 16:497516

Chang PK, Bennett JW, Cotty PJ (2001) Association of aflatoxins biosynthesis and sclerotial development in Aspergillus parasiticus. Mycopathologia 153:41-48

Chang PK, Ehrlich KC, Hua SST (2006) Cladal relatedness among Aspergillus oryzae isolates and Aspergillus flavus $\mathrm{S}$ and $\mathrm{L}$ morphotype isolates. Int J Food Microbiol 108:172-177

Dias N, Santos C, Portela M, Lima N (2011) Toenail onychomycosis in a Portuguese geriatric population. Mycopathologia 172:55-61

Giorni P, Magan N, Pietri A, Bertuzzi T, Battilani P (2007) Studies on Aspergillus section Flavi isolated from maize in northern Italy. Int $\mathrm{J}$ Food Microbiol 113:330-338

Godet M, Munaut F (2010) Molecular strategy for identification in Aspergillus section Flavi. FEMS Microbiol Lett 304:157-168

Goto T, Wicklow DT, Ito Y (1996) Aflatoxin and cyclopiazonic acid production by a sclerotium-producing Aspergillus tamarii strain. Appl Environ Microb 62:4036-4038

Hedayati MT, Pasqualotto AC, Warn PA, Bower P, Denning DW (2007) Aspergillus flavus: Human pathogen, allergen and mycotoxin producer. Microbiology 153:1677-1692

Ito Y, Peterson SW, Wicklow DT, Goto T (2001) Aspergillus pseudotamarii, a new aflatoxin-producing species in Aspergillus section Flavi. Mycol Res 105:233-239

Kimura M (1980) A simple model for estimating evolutionary rates of base substitutions through comparative studies of nucleotide sequences. J Mol Evol 16:111-120

Klich MA (2002) Identification of common Aspergillus species. CBS, Netherlands

Klich MA (2007) Aspergillus flavus: the major producer of aflatoxin. Mol Plant Pathol 8:713-722

Klich MA, Pitt JL (1988) Differentiation of Aspergilus flavus and A. parasiticus and other closely related species. T Brit Mycol Soc 91:99-108

Kozakiewicz Z (1989) Aspergillus species on stored products. CAB International, Wallingford

Kumeda Y, Asao T (2001) Heteroduplex panel analysis, a novel method for genetic identification of Aspergillus section Flavi strains. Appl Environ Microb 67:4084-4090

Kurtzman CP, Horn BW, Hesseltine CW (1987) Aspergillus nomius, a new aflatoxin-producing species related to Aspergillus flavus and Aspergillus tamari. A van Leeuw 53:147-158

Li T-Y, Liu B-H, Chen Y-C (2000) Characterization of Aspergillus spores by matrix assisted laser desorption/ionization time-of-flight mass spectrometry. Rapid Commun Mass Sp 14:2393-2400

Lima-Neto R, Santos C, Lima N, Sampaio P, Pais C, Neves RP (2014) Application of MALDI-TOF MS for requalification of a Candida clinical isolates culture collection. Braz J Microbiol 45:515-522
Midorikawa GEO, Sousa MLM, Silva OF, Dias JSA, Kanzaki LIB, Hanada RE, Mesquita RMLC, Goncalves RC, Alvares VS, Bittencourt DMC, Mille RNG (2014) Characterization of Aspergillus species on Brazil nut from the Brazilian Amazonian region and development of a PCR assay for identification at the genus level. BMC Microbiol 14:138

Nicolau A, Sequeira L, Santos C, Mota M (2014) Matrix-assisted laser desorption /ionisation time-of-flight mass spectrometry (MALDITOF MS) applied to diatom identification: influence of culturing age. Aquat Biol 20:139-144

Novas MV, Cabral D (2002) Association of mycotoxin and sclerotia production with compatibility groups in Aspergillus flavus from peanut in Argentina. Plant Dis 86:215-219

O’Donnell K, Kistler HC, Tacke BK, Casper HH (2000) Gene genealogies reveal global phylogeographic structure and reproductive isolation among lineages of Fusarium graminearum, the fungus causing wheat scab. Proc Natl Acad Sci U S A 97:7905-7910

Passarini MRZ, Santos C, Lima N, Berlinck RGS, Sette LD (2013) Filamentous fungi from the Atlantic marine sponge Dragmacidon reticulatum. Arch Microbiol 195:99-111

Pereira L, Dias D, Santos C, Lima N (2014) The use of MALDI-TOF ICMS as an alternative tool for Trichophyton rubrum identification and typing. Enferm Infecc Microbiol Clin 32:11-17

Pildain MB, Vaamonde G, Cabral D (2004) Analysis of population structure of Aspergillus flavus from peanut based on vegetative compatibility, geographic origin, mycotoxin and sclerotia production. Int $\mathrm{J}$ Food Microbiol 93:31-40

Raper KB, Fennel DI (1965) The genus Aspergillus. Williams \& Wilkins, Baltimore

Razzaghi-Abyaneh M, Shams-Ghahfarokhi M, Allameh A, KazeroonShiri A, Ranjbar-Bahadori S, Mirzahoseini H, Rezaee MB (2006) A survey on distribution of Aspergillus Section Flavi in corn field soils in Iran: population patterns based on aflatoxins, cyclopiazonic acid and sclerotia production. Mycopathologia 161:183-192

Rodrigues P, Venancio A, Kozakiewicz Z, Lima N (2009) A polyphasic approach to the identification of aflatoxigenic and non-aflatoxigenic strains of Aspergillus section Flavi isolated from Portuguese almonds. Int J Food Microbiol 129:187-193

Rodrigues P, Santos C, Venancio A, Lima N (2011) Species identification of Aspergillus section Flavi isolates from Portuguese almonds using phenotypic, including MALDI-TOF ICMS, and molecular approaches. J Appl Microbiol 111:877-892

Rokas A, Payne G, Fedorova ND, Baker SE, Machida M, YU J, Georgianna DR, Dean RA, Bhatnagar D, Cleveland TE, Wortman JR, Maiti R, Joardar V, Amedeo P, Denning DW, Nierman WC (2007) What can comparative genomics tell us about species concepts in the genus Aspergillus? Stud Mycol 59:11-17

Samson RA, Hoekstra ES, Frisvad JC, Filtenborg O (2000) Identification of the common food and airborne fung. In: Samson RA, Hoekstra ES, Frisvad JC (eds) Introduction to food and airborne fungi, 6th edn. Centraalbureau voor Schimmekultures, Utrecht, pp 64-97

Samson RA, Hoekstra ES, Frisvad JC (2004) Introduction to food and airborne fungi, 7 th edn. Wageningen, CBS

Santos C, Paterson RRM, Venancio A, Lima N (2010) Filamentous fungal characterizations by matrix assisted laser desorptionionization time-of-flight mass spectrometry. J Appl Microbiol 108:375-385

Santos C, Lima N, Sampaio P, Pais C (2011) Matrix-assisted laser desorption/ionization time-of-flight intact cell mass spectrometry (MALDI-TOFICMS) to detect emerging pathogenic Candida species. Diag Microbiol Infec Dis 71:304-308

Simões MF, Pereira L, Santos C, Lima N (2013) Polyphasic identification and preservation of fungal diversity: concepts and applications. In: Malik A, Grohmann E, AlvesM (eds) Management of microbial resources in the environment, Chapter 5, ISBN 978-94-007-59305, 410. Springer, The Netherlands, pp 91-116 
Tamura K, Dudley J, Nei M, Kumar S (2007) MEGA4: Molecular Evolutionary Genetics Analysis (MEGA) software version 4.0. Mol Biol Evol 24:1596-1599

Tanaka K, Waki H, Ido Y, Akita S, Yoshida Y (1988) Protein and polymer analyses up to $\mathrm{m} / \mathrm{z} 100000$ by laser ionization time-of-flight mass spectrometry. Rapid Commun Mass Sp 2:151-153

Varga J, Rigo K, Toth B, Teren J, Kozakiewicz Z (2003) Evolutionary relationships among Aspergillus species producing economically important mycotoxins. Food Technol Biotech 41:29-36
White TJ, Bruns T, Lee S, Tailor S (1990) Amplification and direct sequencing of fungal ribosomal RNA genes for phylogenetics. In: Innins MA, Gelfand DH, Sninsky JJ, White TJ (eds) PCR protocols: a guide to methods and applications. Academic, San Diego, pp 315322

Yu J, Whitelaw CA, Nierman WC, Bhatnagar D, Cleveland TE (2004) Aspergillus flavus expressed sequence tags for identification of genes with putative roles in aflatoxin contamination of crops. FEMS Microbiol Lett 237:333-340 